\title{
Dietary Fiber Profiling of Different Parts of Burmese Grape (Baccaurea ramiflora) and Their Application
}

\author{
Kazi NS Rafi ${ }^{1 *}$, Proma Sen ${ }^{1}$, Zia Uddin $^{2}$, Aziz $_{M G^{1}}$ \\ ${ }^{1}$ Department of Food Technology and Rural Industries, Bangladesh Agricultural University, Mymensingh-2202, Bangladesh \\ ${ }^{2}$ General Manager, BRAC Dairy \& Food Project, Gazipur-1700, Bangladesh \\ Email: kazi43656@bau.edu.bd
}

\begin{abstract}
The present study was conducted aiming at isolation and profiling of the crude dietary fiber (DF) (cellulose, hemicellulose, and pectin) from different parts (seed and peel) of the Burmese grape; a local fruit containing numerous health benefits. The extracted and purified fiber was added to yogurt and the sensory quality of the potential prebiotic yogurt was assessed. Major parts of the Burmese grape are seed, peel, and pulp with a calculated portion of around $19.44 \%, 36.11 \%$, and $44.45 \%$ respectively of the whole fruit. Alcohol Insoluble Solids (AIS) were isolated and found at a level of $51.80 \%$ and $72.48 \%$ in the seed and peel respectively. The polysaccharides of the AISs were fractionated by extracting sequentially with suitable solvents into cellulose, hemicellulose, and pectin. The extracted pectin, hemicellulose, and cellulose were found to be $38 \%, 11.56 \%$, and $40 \%$ from the peel and $21.24 \%, 23.36 \%$, and $36.92 \%$ from the seed respectively. The extracted crude DF was then purified and the final content of the pectin, hemicellulose, and cellulose in the peel was found as $7.63 \%, 2.92 \%$, and $32.19 \%$ and in seed $3.04 \%, 1.26 \%$, and $6.34 \%$ respectively. Among all the extracted and purified DF, the hemicellulose content was the lowest and the cellulose content was the highest both in peel and seed. The purified DF was added to yogurt at a level of $0 \%, 1 \%, 1.3 \%$, and $1.5 \%$, to prepare a control and three potential prebiotic yogurt samples. Despite having potential health benefits of prebiotic yogurt, participated panelists preferred control one during sensory evaluation compared to the dietary fiber added yogurt.
\end{abstract}

Keywords: Baccaurea ramiflora, profiling, dietary fiber, Alcohol Insoluble Solid (AIS), extraction, purification, prebiotic, yogurt

\section{Introduction}

In the Southeast Asian region, the Burmese grape or Lotkon (Baccaurea ramiflora) belonged to the family Euphorbiaceae is native and also grows wild in Nepal, India, Myanmar, Bangladesh, South China, Indo-China, Thailand, the Andaman Island, and Peninsular Malaysia. In Bangladesh, Narsingdi, Manikgonj, Gazipur, Netrokona, Kishoreganj, and Sylhet are the well-known Burmese grape producing area. Burmese grape or lotkon is generally being consumed as fresh and popular among the people of all ages in Bangladesh. This Burmese grape also ensures a healthy pregnancy, bone health, common cold, muscular health, provides energy, immunity, and weight $\operatorname{loss}^{[1]}$. It is rich in vitamins, minerals, and claims to have medicinal values. For the treatment of constipation, the fruit juice is mainly used orally. Due to its high content of vitamin C, protein, and iron; B. ramiflora fruit is used as a novel food additive also ${ }^{[2]}$. Amin and Nabi also revealed that Baccaurea ramiflora fruit possesses cytotoxic properties and antioxidant activity so that, this fruit could prevent the diseases caused by oxidative stress and cancer ${ }^{[3]}$. The fruit is similar to berry and the edible portion is aril which is covered by the leathery rind. The whole fruit consisted of three parts; peel, pulp, and seed. Pal et al ${ }^{[4]}$ reported the percentage of different parts of Burmese grape and the average fruit weight $(9 \mathrm{~g})$ and peel weight $(3.75 \mathrm{~g})$. The pulp is only edible part but its amount is quite less compared to the other parts of it. As a result, a major part of the fruit remains inedible $^{[5]}$. The skin and non-edible parts of fruits made agro-waste which needs disposal facilities. Derivatives of cellulosic material from this agro-waste might be economically significant and provide a friendly environment ${ }^{[6]}$.

From cell walls of vegetables, fruits or cereals, different types of polysaccharides (pectin, cellulose, and hemicellulose) and lignin are originated. Both of the soluble and insoluble dietary fibers are being used for food fortification but insoluble dietary fibers are mostly being used these days, for example, the peels of mature but unripe fruits yield $14.1 \%$ pectin and this pectin is useful in the preparation of jellies and jams ${ }^{[7-12]}$.

Copyright (C2020 Kazi NS Rafi, et al

DOI: https://doi.org/10.37256/fse.122020582

This is an open-access article distributed under a CC BY license

(Creative Commons Attribution 4.0 International License)

https://creativecommons.org/licenses/by/4.0/ 
Gibson and Roberfroid ${ }^{[13]}$ described prebiotic as "a non-digestible food ingredient that beneficially affects the host by selectively stimulating the growth and/or activity of one or a limited number of bacteria in the colon, and thus improves host health". They also categorized prebiotics by only a few compounds of the carbohydrate group such as short and longchain $\beta$-fructans [FOS and inulin], lactulose, and GOS. Different dietary fiber-enriched food products are the natural source of prebiotics, which has a significant role in human health ${ }^{[14]}$. According to [15], the following standards are used to categorize a compound as a prebiotic: (i) it ought to be resistant to the acidic $\mathrm{pH}$ of the stomach, can't be hydrolyzed by using mammalian enzymes, and additionally should not be absorbed in the gastrointestinal tract, (ii) it can be fermented with the aid of intestinal microbiota, and (iii) the increase and/or undertaking of the intestinal microorganism can be selectively encouraged with the aid of this compound and this method improves host's intestines fitness. Besides ensuring healthful intestines, prebiotics is undoubtedly necessary for many facts, for example: due to the bioprocess, they produce microbial biomass, growing the range of defecations; help as a substitute to the probiotics, due to the fact they inhibit the multiplication of pathogens. They forestall diarrhea conditions and different ailments like colon cancer; they set up favorable mechanisms for immunomodulation. Prebiotics helps in the absorption and bioavailability of calcium and iron, and lipid metabolism also. These act as useful components like sugar and fats substitutes. The sensorial characteristics in food are also promoted by prebiotics ${ }^{[16-17]}$.

For the development of prebiotic foods, it needs a source of food that contains low fiber. Dairy products can fulfill this requirement, as no dietary fiber is present in $\mathrm{it}^{[18]}$. Nowadays, functional dairy food products fortified with dietary fiber are gaining attention and popularity because of their functional quality and health benefits. The recommended daily intake of fiber is about $38 \mathrm{~g}$ for men and $25 \mathrm{~g}$ for women ${ }^{[19]}$. Fiber-rich food has low energy density with high volume and may promote satiety and satiation. These types of foods can control energy balance. Fiber has the ability of binding bile acids and metabolites of cholesterol that play a vital function in digestion and absorption of lipids in the small intestine, decreasing blood cholesterol, regulating blood glucose ranges for diabetes management, producing short-chain fatty acids, and merchandising the increase of recommended intestine micro flora ${ }^{[20-24]}$. Many research findings show that the high intake of dietary fiber reduces the risk of cardiovascular disease, type-2 diabetes, obesity, mortality, and also the risk of developing different types of cancers. Nowadays dietary fibers are gaining popularity for their ability to regulate body weight and high intakes have also shown a smaller weight gain in prospective experimental studies ${ }^{[25]}$. Foods with high dietary fiber content also play a significant role in the prevention of several diseases i.e., increasing stool weight and decreasing colonic transit time which leads to the prevention of colonic diverticulosis and constipation. Food can be considered as a source of fiber when the product contains at least $1.5 \mathrm{~g}$ of fiber per $100 \mathrm{kcal}(418.68 \mathrm{~kJ})$, while product containing at least $3 \mathrm{~g}$ of fiber per $100 \mathrm{kcal}(418.68 \mathrm{~kJ})$ can be classified as a high fiber containing food ${ }^{[26]}$.

The interaction between fiber and food components may change the bioavailability of nutrients, texture, or flavor during processing. The consumption of dietary fiber may impact the absorption of nutrients. In the case of glucose, the total fiber content of meals can prolong the glycemic response but soluble fiber decrease blood glucose where purified insoluble fibers have little or no impact on postprandial blood glucose ${ }^{[27]}$. According to Hashim et al. ${ }^{[9]}$ and Crispín-Isidro et al. ${ }^{[28]}$, the color and texture of fiber-enriched products may vary with the color and source of the fiber.

Yogurt is a rich source of nutrition and might be alternative vehicle for the development of dietary fiber-enriched foods. For this, several authors studied the texture and characteristics of yogurt due to the addition of different dietary fibers, where nutritional and sensory aspects both were concerned ${ }^{[29-30]}$. Keeping observations above in mind, this investigation has been undertaken for the following objectives: (a) To isolate and profile of the crude dietary fiber (cellulose, hemicellulose, and pectin) from different parts (seed and peel) of Burmese grape; (b) To observe the effect of extracted dietary fiber on the quality of fermented dairy products, i.e, yogurt.

\section{Materials and methods}

\subsection{Materials}

Fresh Burmese grapes, fresh raw cow's milk, commercial yogurt culture, and sugar used in this study were obtained from the local market.

\subsubsection{Equipment and instruments}

All experiments were carried out in the Food Chemistry and Analysis Laboratory of the Department of Food Technology and Rural Industries equipped with necessary apparatus, equipment, and instruments.

\subsubsection{Chemical reagents}

Chemicals like 99.5\% pure alcohol/ethanol (Merck), sodium hydroxide ( $\mathrm{NaOH})($ Merck), hydrochloric acid (HCl) 
(Merck) were laboratory grade and purchased from Merck, India.

\subsection{Methods}

\subsubsection{Sample preparation and characterization of different parts of Burmese grape}

Burmese grapes were collected from the local market. Firm and mature fruits having golden to yellow color and without blemishes and any signs of dark yellow color on the skin were selected. Selected fresh fruits were washed thoroughly. All the stems, cavities, and other waste materials were removed from them. Peels were collected from the Burmese grape by scraping them properly and manually. Pulp was collected by extracting juices from fruit bulbs which resulted in seeds as waste. All the separated parts were kept in 3 different containers and frozen at $-20^{\circ} \mathrm{C}$. Previously stored frozen samples were brought to room temperature for the preparation of further analysis. Different parts of Burmese grape like seed, peel, and pulp were expressed as a percentage of the total weight by using equation (1).

$$
\% \text { Weight of different parts }=\frac{\text { Parts Content }}{\text { Total fruit weight }} \times 100
$$

To determine moisture content and dry matter content in different parts (seed and peel) of Burmese grape, equation no. (2) and (3) were used.

$$
\% \text { Moisture content }=\frac{(\text { Initial } \text { weight }- \text { Dried } \text { weight })}{\text { Initial } \text { weight }} \times 100
$$

$\%$ Dry matter $=(100-\%$ Moisture content $)$

\subsubsection{Preparation of dried powder samples from Burmese grape peel and seed}

Firstly, the frozen samples were brought to room temperature $\left(25^{\circ} \mathrm{C}\right)$ and kept for 2 hours to get them ready for the next step of processing. The samples (peel and seed) were spread on the polythene lined trays. Trays with samples were then placed in a cabinet dryer $\left(65^{\circ} \mathrm{C}\right)$ for 7 days to get them dried. Then the dried samples were ground by using a mechanical grinder. The dried powder was further ground by a blending machine to make the powder particles finer. After that, the powder was collected in an LDP (Low-density polyethylene) bag and sealed by a sealing machine. Finally, the powder was stored at a desiccator for a moisture-free environment.

\subsection{Extraction of polysaccharides from Burmese grape}

\subsubsection{Isolation of Alcohol Insoluble Solids (AIS)}

The method reported by [31] with slight modifications was used for AIS preparation. Modifications were applied only in the methods for isolation of AIS. The AIS from the dried powder (peel and seed) of Burmese grape were obtained by washing with $95 \%$ alcohol. About $25 \mathrm{~g}$ powders were mixed with $250 \mathrm{ml}$ of $95 \%$ ethanol at a ratio of 1:10 (w/v). The powder sample was then homogenized in boiling alcohol $\left(70^{\circ} \mathrm{C}\right)$ using a Magnetic Stirrer coupled with Hot Plate (Coslab) at a speed of $3000 \mathrm{rpm}$ for $20 \mathrm{~min}$. The powder to alcohol ratio was maintained at 1:10 (w/v). The suspension was then boiled for another $40 \mathrm{~min}$ and then cooled and centrifuged at $4000 \mathrm{rpm}$ for $20 \mathrm{~min}$. The two layers thus formed during centrifugation were separated carefully. The supernatant was decanted and AIS was prepared by re-suspending the pellets treated as described above. Washing continued until the supernatant became clear. The obtained AIS were then oven-dried and stored ${ }^{[32]}$. The percentages of isolated AIS were calculated according to equation (4).

$$
\% \text { Isolated AIS }=\frac{\text { Isolated amount }}{\text { Initial amount }} \times 100
$$

\subsubsection{Sequential extraction of Alcohol Insoluble Solids (AIS)}

The sequential extraction of AIS was carried out according to the method of [33] with slight modification. Modifications were applied only in the methods of centrifugation and polysaccharide fraction isolation. Firstly, the AIS sample $(2.5 \mathrm{~g})$ was taken and mixed with $250 \mathrm{ml}, 50 \mathrm{mM} \mathrm{NaOH}$ solutions at a ratio of 1:10 (w/v). The solution was sonicated for 30 minutes at $40 \mathrm{KHz}$ and then centrifuged at $4000 \mathrm{rpm}$ for $20 \mathrm{~min}$. After that, the supernatant was collected and dried at $70^{\circ} \mathrm{C}$ in a hot air oven for isolating the first fraction (pectin). Sediment remained in the centrifuge tube was 
further treated with $4 \mathrm{M} \mathrm{NaOH}$ solution at a ratio of 1:10 (w/v). After sonication and centrifugation of the solution, the supernatant was collected and dried for hemicellulose fraction. The collected pellet was washed with de-ionized water and collected as cellulose fraction. Finally, the powdered sample of cellulose, hemicellulose, and pectin was kept at desiccators for further use. The same procedure was followed for the sequential extraction of pectin, hemicellulose, and cellulose from AIS of seed powder. Percent extraction and percent loss were calculated by following no.(5) and (6) equations.

$$
\begin{aligned}
& \% \text { Extraction }=\frac{\text { Extracted amount }}{\text { Amount taken }} \times 100 \\
& \% \text { Loss }=(100-\% \text { Extraction })
\end{aligned}
$$

\subsubsection{Purification of dietary fiber sample for yogurt preparation}

The total amount of dietary fiber (Cellulose, Hemicellulose, and Pectin) extracted from $2.5 \mathrm{~g}$ of AIS of both peel and seed sample was purified. The microfiltration method was used in this study to purify dietary fiber for yogurt preparation according to the recommendation of research findings of purification of dietary fiber ${ }^{[34]}$. The crude dietary fiber was first mixed with distilled water at a ratio of 1:10 (w/v). The $\mathrm{pH}$ of the solution was measured $(>7)$ and adjusted to 5.88 and then filtered by passing through $0.45 \mu \mathrm{m}$ filter paper under minimum vacuum to regulate the filtration. It allowed the passing of salts and other low molecular particles but retained dietary fiber on the paper. This step is continued for several times. Finally, the pure dietary fiber was collected on the filter paper and then dried at $70^{\circ} \mathrm{C}$ inside a hot air oven for 20 minutes, and then they were collected and stored inside the desiccator for yogurt preparation. Dietary fiber was being extracted and purified from different portions of Burmese grape (seed and peel) to make proper profiling of dietary fiber in this fruit. Percent purified and percent wastage of dietary fiber from both peel and seed were calculated by using equation no. (7) and (8).

$$
\begin{aligned}
& \% \text { Purified }=\frac{\text { Purified } \text { amount }}{\text { Extracted amount }} \times 100 \\
& \% \text { Wastage }=(100-\% \text { Purified })
\end{aligned}
$$

\subsubsection{Preparation of dietary fiber enriched yogurt}

Preparation of dietary fiber enriched yogurt was carried out following the standard procedure of yogurt preparation. A mixed dietary fiber was prepared by blending the extracted and purified dietary fiber (such as cellulose, hemicellulose, and pectin) in such a way that the (Hemicellulose + Pectin): Cellulose would be equal to 1:2. This type of the formulation was done due to the collected content of hemicellulose and pectin was less than the cellulose content. The fresh raw cow milk was standardized to 3\% milk fat and 12\% milk solids not fat (MSNF) using fresh raw skimmed cow milk and skimmed milk powder, for the fortification of yogurt 1\%, 1.3\%, and 1.5\% of that mixed dietary fiber was incorporated following the recommendation of several research findings of the fortification of yogurt with dietary fiber ${ }^{[35-37]}$. At first, the mixed fiber at the selected levels was blended with 5\% sugar and then added them to the standardized milk for the yogurt preparation. A yogurt sample was prepared without adding fiber and was defined as control. All the fortified milk samples thus prepared were heated at $90^{\circ} \mathrm{C}$ for $15 \mathrm{~min}$. Then they were cooled to approximately $42^{\circ} \mathrm{C}$ and inoculated with $2 \%$ commercial culture containing Lactobacillus bulgaricus and Streptococcus thermophilus microorganisms, and filled in plastic cups. Then yogurt cups were incubated to a final $\mathrm{pH}$ of 4.4 at $37^{\circ} \mathrm{C}$ for 4.5 to $5 \mathrm{hrs}$ for coagulation. After completing proper coagulation, the yogurt cups were cooled to ambient temperature $\left(15\right.$ to $\left.20^{\circ} \mathrm{C}\right)$ and transferred to the refrigerator $\left(5^{\circ} \mathrm{C}\right)$. Finally, sensory evaluation was carried out on fresh yogurt after 24 hours of storage in refrigeration ${ }^{[9,38-39]}$.

\subsection{Sensory evaluation of dietary fiber enriched yogurt}

The sensory evaluation of dietary fiber enriched yogurt was carried out by a testing panel of 9 trained judges, all of who had two years' experience of using the guidelines for the use of quantitative response scales for sensory analysis (ISO, 4121:2003). Panelists were regulated to give mark samples for color, flavor, texture, and overall acceptability in a 9-point hedonic scale test in a 45 min training session. The defects and attributes of samples like off-flavor, gritty texture, whey syneresis, grainy, appearance, color were scored ranging from 1 (dislike extremely) to 9 (like extremely). Dietary fiberenriched yogurt was evaluated for color, flavor, texture, and overall acceptability. The yogurt samples were marked with 
a three-digit random number to make the evaluation unbiased. Samples were denoted as $232=\mathrm{S}_{1}=1.5 \%$ dietary fiber enriched yogurt; $321=\mathrm{S}_{2}=1.3 \%$ dietary fiber enriched yogurt; $213=\mathrm{S}_{3}=1 \%$ dietary fiber enriched yogurt; $312=\mathrm{S}_{4}=$ yogurt with $0 \%$ dietary fiber which was the control sample. All the samples of dietary fiber enriched yogurt and control yogurt were given to the panelists with a standard evaluation sheet and asked them to give scores of each sample according to their preference ${ }^{[40]}$.

\subsection{Statistical analysis}

All the analyses were carried out triplicate and presented as the mean. The average of all the data obtained from the sensory evaluation was represented in the Radar chart and then those were analyzed to assess statistically significant differences among the samples by using the two ways ANOVA (Analysis of Variance) with Microsoft Office Excel, 2013. Also, satisfactory results of preference test for the color, flavor, texture, and overall acceptability for the final product (dietary fiber enriched yogurt) was obtained by conducting the LSD (Least Significant Difference) test at $\mathrm{p}<0.05$.

\section{Results and discussion}

\subsection{Characterization of different parts of Burmese grape}

Different parts of Burmese grape like seed, peel, and pulp were separated and expressed as the percentage of the total weight of fruit. The major parts of this fruit are seed, peel, and pulp having a contribution of $19.44 \%, 36.11 \%$, and $44.45 \%$ of the whole weight of the fruit respectively. While nearly half (about 44\%) of the total weight of Burmese grape showed edible, the peel and seed parts accounted to the rest half (about $56 \%$ ) of the whole weight remained as inedible. Pal et al. ${ }^{[4]}$ reported the percentage of the peel of Burmese grape to about $41 \%$ that closely tended to our experimental value for the peel.

\subsection{Major compositions of different parts of Burmese grape}

Moisture content, dry matter content, and AIS in different parts (seed and peel) of Burmese grape were determined. The percentage of major components of different parts of the fruit is presented in Table 1.

Table 1. The portion of major compositions

\begin{tabular}{cccc}
\hline Burmese grape & Moisture content (\%) & Dry matter (\%) & \% Isolated AIS \\
\hline Seed & 14.35 & 85.65 & 51.80 \\
Peel & 20.35 & 79.65 & 72.48 \\
\hline
\end{tabular}

*AIS means Alcohol Insoluble Solids from dry matter.

According to Table 1, the moisture content of peel portions of Burmese grape is slightly higher than that of seed, and accordingly, dry matter (DM) got higher in seed than that of the peel. In an investigation of [41], for seven different fruits, peels were reported having contained the highest moisture content ranging from $65.7 \%$ to $92.6 \%$, and the seeds ranging from $5.8 \%$ to $67.2 \%$. Though the investigated fruits were different from Burmese grape, in comparison to seed and peel moisture, it supports our findings as the peel contains higher moisture content than the seed of Burmese grapes. The AIS contents of some fruit byproducts like passion fruit seed, mango, quince, and citrus fruit wastes were reported to be $70.5 \%$, $30.7-49.7 \%, 27.8-37.5 \%$, and $45.0-75.0 \%$ respectively ${ }^{[42-43,31,44]}$. These findings were supported to the isolated content of AIS from seed and peel which are precisely agro-waste of Burmese grape fruit. According to the opinion of [45], variation in the extracted AIS content may be held for the action of native enzymes, such as pectinase, hemicellulase, and cellulase on the conversion of cellulose, hemicellulose, pectin, and starch to soluble constituents with fruit growth and development.

\subsection{Sequential extraction of polysaccharides from AIS of Burmese grape seed and peel}

Among the major constituents present in Burmese grape, polysaccharides play an important role in many aspects like the firmness of the cell wall and fruit structure. Alcohol insoluble solids (AIS) were considered as suitable preparations for the sequential extraction of polysaccharides ${ }^{[46]}$. AISs of both of the Burmese grape peel and seed were prepared and fractionated into pectin, hemicellulose, and cellulose. The percentage of extraction and loss were calculated and presented in Table 2. 
Table 2. Sequential extraction of AIS from peel and seed powder

\begin{tabular}{cccccc}
\hline \multirow{2}{*}{ Samples } & Amount took $(\mathrm{g})$ & \multicolumn{2}{c}{ Peel } & Seed \\
\cline { 3 - 5 } & & \% Extraction & \% Loss & \% Extraction & \% Loss \\
\hline AIS & 2.5 & 38 & & 21.24 & \\
Pectin & & 11.56 & & 23.36 & \\
Hemicellulose & & 40 & & 36.92 & 18.48 \\
Cellulose & 2.5 & 89.56 & 10.44 & 81.52 & 18.48 \\
Total & &
\end{tabular}

According to Table 2, pectin and cellulose were the predominant polysaccharides in the Burmese grape peel and they constituted about four-fifths ( $80 \%$ ) of the total polysaccharides. In total, about $90 \%$ of the AIS of Burmese grape peel were recovered and around $10 \%$ was lost during extraction. Among all the extracted polysaccharides, cellulose (40\%) was found as the largest fraction of polysaccharides; followed by the pectin (38\%) where hemicellulose showed the lowest (about $12 \%$ ) fraction of dietary fiber in the Burmese grape peel. Extraction resulted from peel also indicated that the sum of soluble polysaccharides as pectin and hemicellulose fraction (about 50\%) was higher than the insoluble cellulose fraction. This cellulose content (40\%) in Burmese grape peel was found to be almost similar to a research finding $(42 \%)$ reported by [6]. The finding was relatively close to the cellulosic material of other common sources like cotton, jute, bamboo, etc. as well ${ }^{[47]}$.

As shown in Table 2, out of about $82 \%$ of dietary fiber present in seed AIS, about $45 \%$ of those were soluble while about $37 \%$ was insoluble dietary fiber. A significant amount of dietary fiber (about 18\%) was lost during different extraction steps. Among the extracted polysaccharides, the highest fraction of polysaccharide was cellulose (about 37\%) followed by hemicellulose (about 23\%) and the lowest fraction was pectin which was around $21 \%$ in the seed AIS. The overall variation of fractionated cellular components of Burmese grape might be described by the loss that occurred during different extraction steps ${ }^{[48]}$. Again, probably due to the strong bond between pectin and other cell wall components, the preparation method of AIS (like drying) may affect the extraction of pectin from AIS by converting pectin molecule insoluble ${ }^{[49-50]}$.

\subsection{Purification of extracted dietary fiber from peel and seed of Burmese grape}

Extracted dietary fibers from AIS were then purified by dialyzing the extracted fraction with distilled water. Percent purified and percent wastage from both peel and seed were calculated and the results of the purified dietary fiber are shown in Table 3.

Table 3. Purification of extracted dietary fiber from peel and seed powder

\begin{tabular}{ccccc}
\hline \multirow{2}{*}{ Samples } & \multicolumn{2}{c}{ Peel } & & Seed \\
\cline { 2 - 5 } & \% Purified & \% Wastage & \% Purified & \% Wastage \\
\hline Pectin & 7.63 & & 3.04 & \\
Hemicellulose & 2.92 & & 1.26 & \\
Cellulose & 32.19 & & 6.34 & 89.36 \\
Total & 42.74 & 57.26 & 10.64 & \\
\hline
\end{tabular}

Table 3 presents that less than half (about 43\%) of the crude dietary fiber was obtained as purified dietary fiber after purification and the rest around $57 \%$ was removed as wastage from the peel. Among the purified dietary fiber, the predominant fraction was cellulose (about 32\%), followed by pectin (about $8 \%$ ) and the lowest fraction was hemicellulose (about 3\%). Out of the total dietary fiber, around three fourth of them was the insoluble dietary fiber and about only one fourth was the soluble dietary fiber in the Burmese grape peel. On the other hand, the recovery of total dietary fiber from the seed AIS was almost four times lower than that of the peel AIS. After purification, the highest purified dietary fraction was cellulose (around 6\%) followed by pectin (about 3\%) and around 1\% hemicelluloses being recovered as the lowest purified fraction from Burmese grape seed. The soluble solids like minerals, colors, other particles were removed during purification as wastage. Soluble fibers might also be removed during filtration as wastage. The release rate of these soluble solids may vary with different heating temperature, heating time, and methods during purification due to the hydrolyzing tendency of soluble polysaccharides of fruits and vegetables ${ }^{[40]}$. Different purified dietary fiber from the extracted crude dietary fiber of peel and seed AIS were shown in Figure 1. 

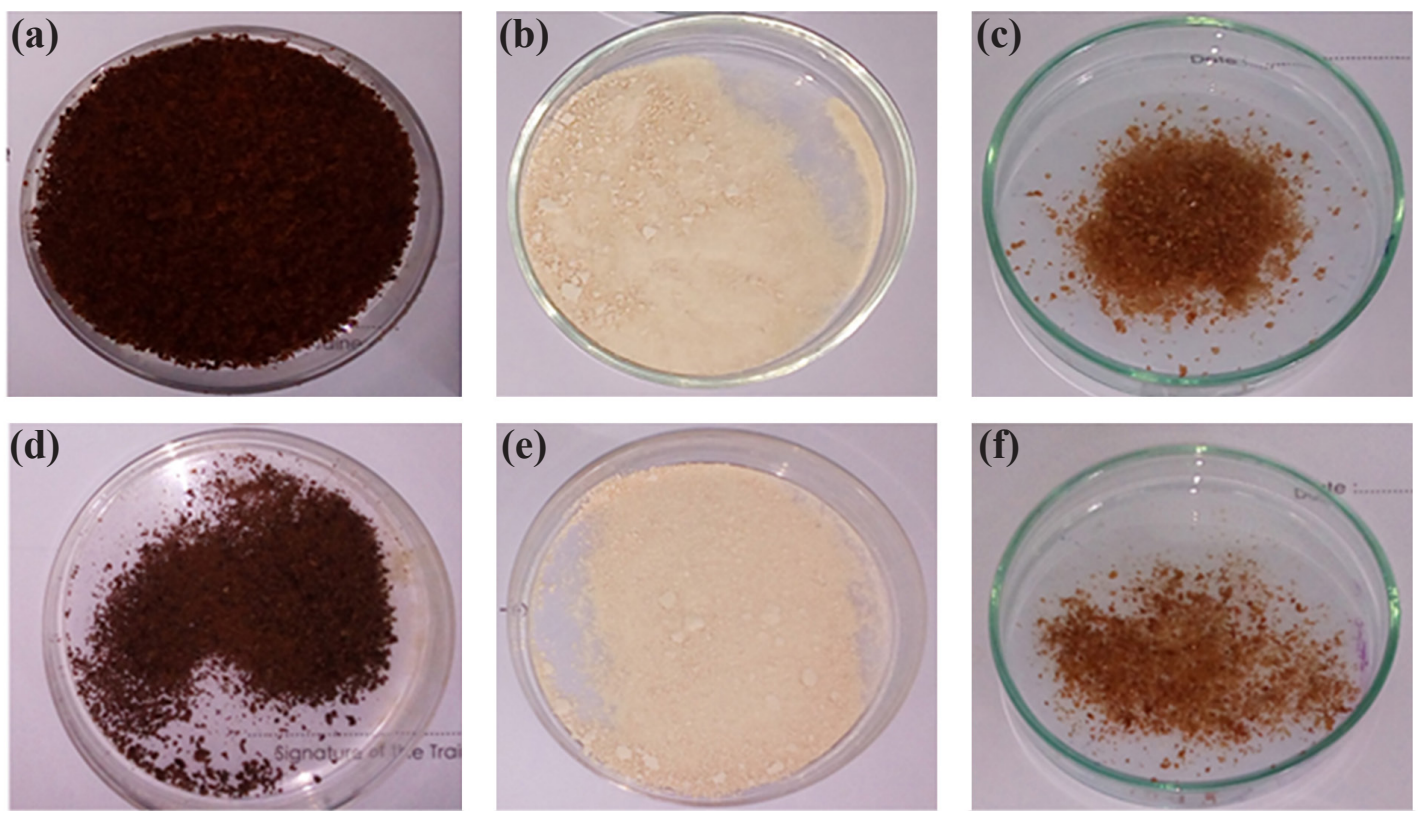

Figure 1. Different purified dietary fiber from the crude dietary fiber of peel and seed AIS

(a) Peel Cellulose, (b) Peel Hemicellulose, (c) Peel Pectin, (d) Seed Cellulose, (e) Seed Hemicellulose, (f) Seed Pectin

\subsection{Sensory evaluation of dietary fiber enriched yogurt}

The potential prebiotic yogurts made with the purified dietary fiber extracted from Burmese grape peel and seed were evaluated by a panel having nine testers. Different samples for sensory evaluation were shown in Figure 2. The graphical representation of mean scores of color, flavor, texture, and overall acceptability preference of the fortified potential prebiotic yogurts are presented in Figure 3. For color, flavor, and overall acceptance, the highest scores $(8.44,7.89$, and 8.11 respectively) were secured by the $S_{4}$ sample whereas the lowest scores $(6.33,6$, and 6.11 respectively) were given for the $\mathrm{S}_{2}$ sample by the panelists. Concerning texture preference, $\mathrm{S}_{1}$ and $\mathrm{S}_{4}$ samples were scored 8 as the highest, and $\mathrm{S}_{3}$ samples scored the lowest having the mean figure 6.22 .
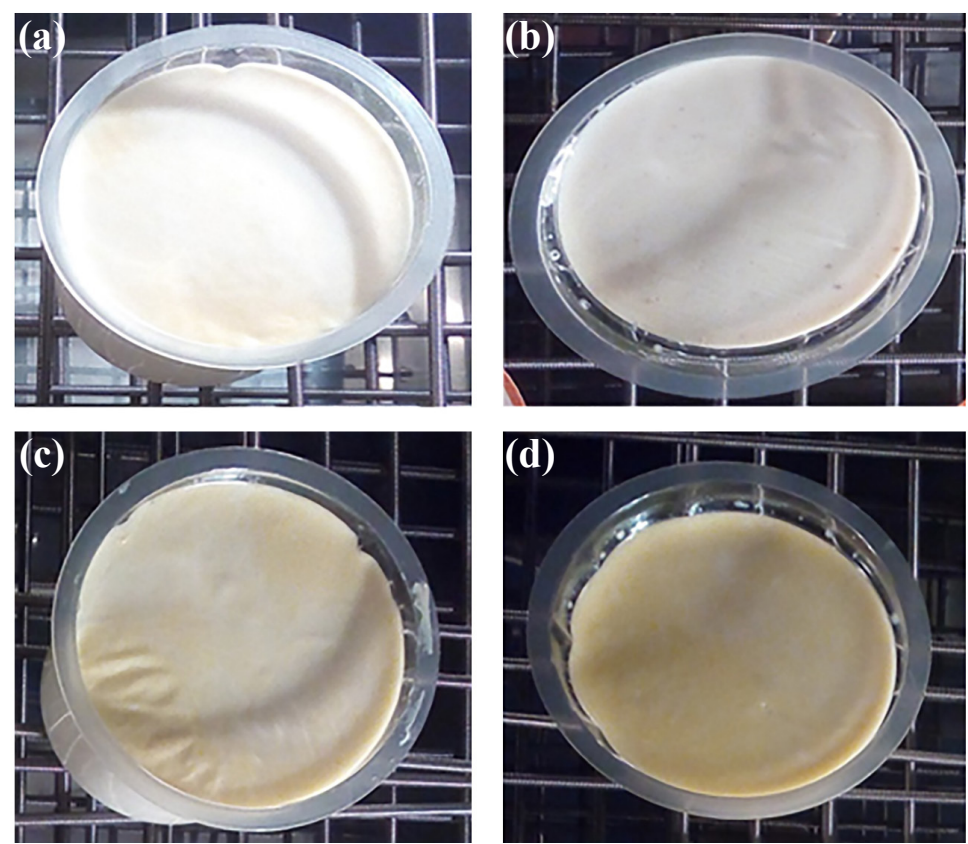

Figure 2. Different samples for sensory evaluation

Where, (a) sample $S_{1}=1.5 \%$ dietary fiber enriched yogurt; (b) sample $S_{2}=1.3 \%$ dietary fiber enriched yogurt;

(c) sample $S_{3}=1 \%$ dietary fiber enriched yogurt; (d) sample $S_{4}=$ yogurt with $0 \%$ fiber and all the yogurt contained $5 \%$ sugar in them 
A two-way analysis of variance (ANOVA) was carried out to find if there were any significant differences among the testers and the samples tested by the testers and the result was presented in Table 4.

Table 4. Mean sensory scores on sensory attributes of yogurt

\begin{tabular}{ccccc}
\hline Sample & \multicolumn{3}{c}{ Sensory attributes } & Overall acceptability \\
\cline { 2 - 5 } & Color & Texture & Flavor & $7.11^{\mathrm{b}}$ \\
$\mathrm{S}_{1}$ & $7.78^{\mathrm{a}}$ & $8^{\mathrm{a}}$ & $6.89^{\mathrm{b}}$ & $6.11^{\mathrm{c}}$ \\
$\mathrm{S}_{2}$ & $6.33^{\mathrm{b}}$ & $6.56^{\mathrm{b}}$ & $6^{\mathrm{c}}$ & $6.22^{\mathrm{bc}}$ \\
$\mathrm{S}_{3}$ & $6.67^{\mathrm{b}}$ & $6.22^{\mathrm{b}}$ & $6.11^{\mathrm{c}}$ & $8.11^{\mathrm{a}}$ \\
$\mathrm{S}_{4}$ & $8.44^{\mathrm{a}}$ & $8^{\mathrm{a}}$ & $7.89^{\mathrm{a}}$ & 0.924 \\
\hline LSD Values & 0.71 & 0.67 & 0.74 & \\
\hline
\end{tabular}

Where, $S_{1}=1.5 \%$ dietary fiber enriched yogurt; $S_{2}=1.3 \%$ dietary fiber enriched yogurt; $S_{3}=1 \%$ dietary fiber enriched yogurt; $\mathrm{S}_{4}=$ Control yogurt with $0 \%$ dietary fiber. Significance level: significant at $\mathrm{p}<0.05$, different superscript letters on the same column indicate significant differences, same superscript indicates non significances.

Obtained results of the two-way Analysis of Variance (ANOVA), suggests that there were no significant differences among the testers at $\mathrm{p}<0.05$, and on the other hand there were significant differences among the potential prebiotic yogurt samples at $\mathrm{p}<0.05$.
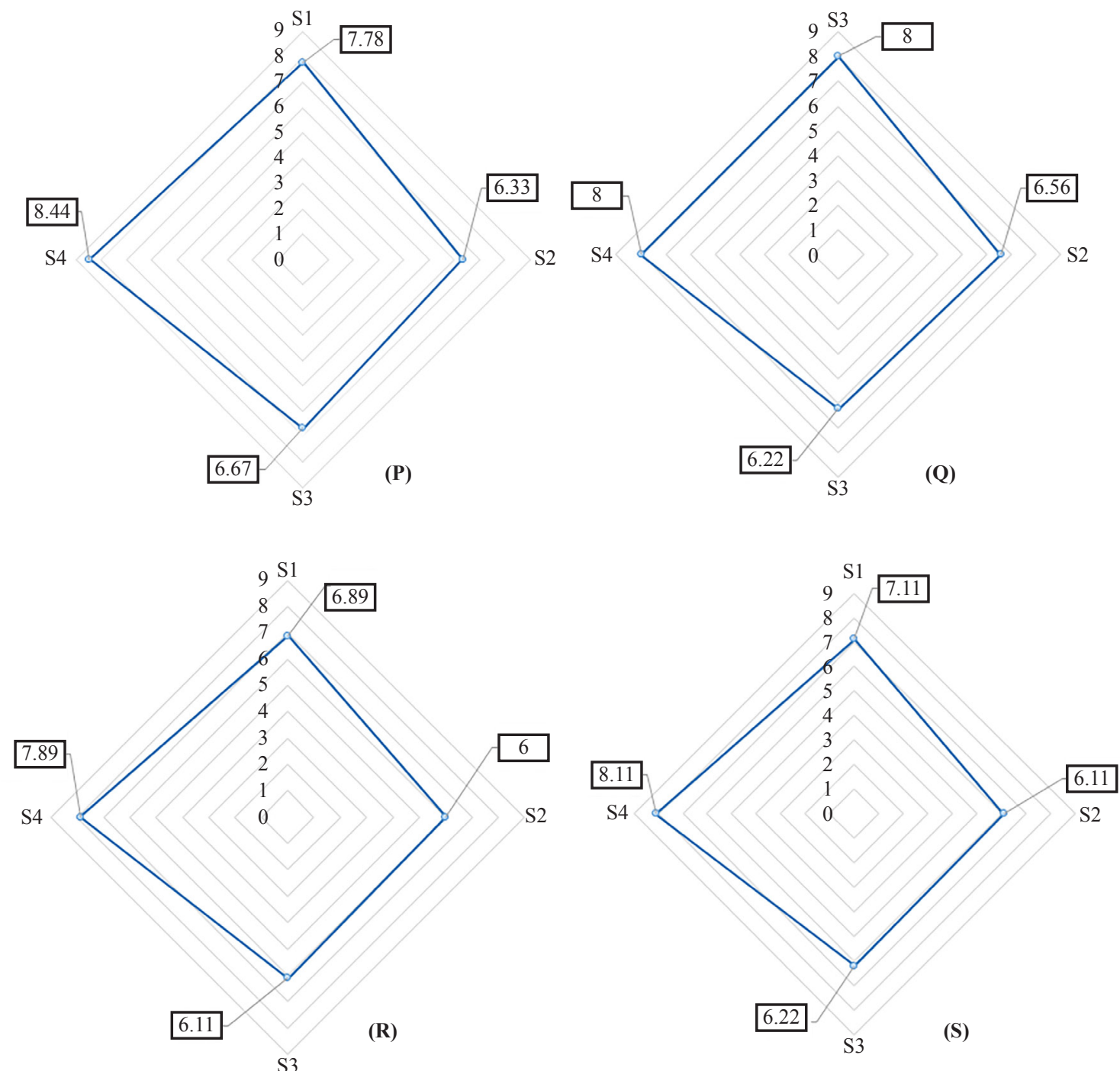

Figure 3. A graphical representation of mean scores for different attributes of the dietary fiber enriched yogurt Where, (P) for color, (Q) for texture, (R) for flavor, and (S) for overall acceptability 
It can be concluded from the results of the two-way Analysis of Variance (ANOVA), that the panelists possessed a similar sensitivity, and hence all of them were fit for carrying out the sensory evaluation of the potential prebiotic yogurt and there were no significant differences among them. Sensory attributes (color, flavor, texture, and overall acceptability) of the dietary fiber enriched potential prebiotic yogurt were significantly different and these attributes were significantly affected by the addition of dietary fiber at different levels in the yogurt where $\mathrm{S}_{1}$ ranked as "Liked Moderately", $\mathrm{S}_{2}$ and $\mathrm{S}_{3}$ as "Liked Slightly" and $\mathrm{S}_{4}$ as "Liked Very Much".

From the observation of $[9,38]$, it can be concluded that the color of yogurt is varying with the color of the fiber source. Flavor quality may decrease by fiber addition that was reported by [9] and it may support the result for flavor preference of fiber-enriched yogurt in this investigation. According to [26], fiber size has an important impact on yogurt formulation that may cause variation in general acceptance. In our investigation, this reason may influence the overall acceptance of samples with fibers. The deep gritty texture and grainy flavor of fiber-enriched yogurt was found by [26]. Kip et al. ${ }^{[51]}$ used fiber to develop the creaminess of the yogurt and Crispín-Isidro et al. ${ }^{[28]}$ observed the effect of fiber on the taste and texture for the improvement of yogurt and indicated fibers as a 'filler' between yogurt components that may increase gel firmness. Furthermore, the interaction between caseins and the higher concentration of fibers may enhance the G' (which measures the elastic component) and G" (which measures the plastic component) that provide a stronger texture of yogurt. According to [52-54] some functional properties such as texture, water holding capacity, oil holding capacity, emulsification, and/or gel formation, the bulking agent in reduced-sugar applications, and shelf-life of processed foods may be improved by fiber. From the investigation of [55], and [28], the ability of fiber to interact through hydrogen bridges with charges moieties on the surface of the protein may control synergists that have an effective influence on sensory attributes of fiber fortified yogurt.

\section{Conclusion}

The study suggests that more than half (about $56 \%$ ) of the non-edible parts $(19.44 \%$ seed and $36.11 \%$ peel) of Burmese grapes might be used as a great source of different polysaccharides; like cellulose, hemicelluloses and pectin; and these could be used as prebiotics to create functional foods, like yogurt, with health benefits. To achieve the specific objectives, the AISs were isolated from seed and peel at $51.80 \%$ and $72.48 \%$ respectively. For characterizing polysaccharides, sequential extraction of pectin, hemicellulose, and cellulose was carried out and found as $38 \%, 11.56 \%$, and $40 \%$ from peel respectively; whereas from seed, sequentially extracted pectin, hemicellulose and cellulose were $21.24 \%, 23.36 \%$, and $36.92 \%$ respectively. Peel had around $90 \%$ crude dietary fiber that was higher than the content of seed (about 82\%). After purification, more pure dietary fiber was found in Burmese grape peel (about 43\%) which was higher than in seed (about 11\%). Finally, those purified dietary fibers were used as prebiotics for preparing functional dairy food like yogurt. Among the sensory evaluation of the prepared yogurt samples containing $1 \%, 1.3 \%$ and $1.5 \%$ of purified dietary fiber, $1.5 \%$ of dietary fiber-containing yogurt provides a better result. However, overall consideration, panelists preferred the control one compared to the potential prebiotic yogurt.

\section{Acknowledgments}

The author acknowledges all the co-authors for their valuable involvement during whole research work. Aziz M.G. conceptualized the idea and directed the study, delivered laboratory facilities, and finally made English correction; Kazi N.S. Rafi designed experiments, carried out laboratory works, analyzed the data, and wrote the manuscript; Proma Sen assisted in laboratory works and in writing and editing the manuscript; Zia Uddin provided analysis facilities and contributed to language editing. All authors have read and agreed to the published version of the manuscript.

\section{References}

[1] Rahman SML, Bhuyan M, Mustakim A, Sarker J, Hussain M. Fruit characteristics, yield contributing characters and yield of some Lotkon genotypes under northeastern region of Bangladesh. Int J Sustain Crop Prod. 2014; 1(9): 8-10.

[2] Goyal AK, Mishra T, Sen A. Antioxidant profiling of Latkan (Baccaurea ramiflora Lour.) wine. Indian J Biotechnol. 2013; 12(1): 137-139.

[3] Amin R, Nabi MdN. Evaluation of cytotoxic and antioxidant activity of different fractions of methanolic extract of Baccaurea ramiflora (Lour.) fruits. Int Curr Pharm J. 2015; 4(6): 386-389. Available from: doi:10.3329/icpj. v4i6.23288 
[4] Pal, RK, Bhowmick N, Suresh. C. Latka (Baccaurea sapida Muell. Arg.)-An under-exploited minor fruit crop of West Bengal. Indian Horticulture Congress. 2008; 3: 325.

[5] Raghavan M, Ramjan M. Burmese grape (Baccaurea ramiflora Lour.): A promising fruit crop for future generations. $J$ Med Plants Stud. 2018; 6(3): 50-52.

[6] Ruma SA, Rashid F, Sathi MRA, et al. Isolation of cellulosic materials from wastes of fruits of Bangladesh and their derivatization. 2014; 3(2): 400-403.

[7] Annonymous. Baccaurea. The Wealth of India: A Dictionary of Indian Raw Materials and Industrial Products. Raw Materials. Industrial Products. 1951; 2: 427.

[8] Bertolino M, Belviso S, Dal Bello B, et al. Influence of the addition of different hazelnut skins on the physicochemical, antioxidant, polyphenol and sensory properties of yogurt. LWT-Food Sci Technol. 2015; 63(2): 1145-1154. Available from: doi:10.1016/j.lwt.2015.03.113.

[9] Hashim IB, Khalil AH, Afifi HS. Quality characteristics and consumer acceptance of yogurt fortified with date fiber. $J$ Dairy Sci. 2009; 92(11): 5403-5407. Available from: doi:10.3168/jds.2009-2234.

[10] Sah BNP, Vasiljevic T, McKechnie S, Donkor ON. Effect of refrigerated storage on probiotic viability and the production and stability of antimutagenic and antioxidant peptides in yogurt supplemented with pineapple peel. $J$ Dairy Sci. 2015; 98(9): 5905-5916. Available from: doi:10.3168/jds.2015-9450.

[11] Sendra E, Fayos P, Lario Y, Fernández-López J, Sayas-Barberá E, Pérez-Alvarez JA. Incorporation of citrus fibers in fermented milk containing probiotic bacteria. Food Microbiol. 2008; 25(1): 13-21. Available from: doi:10.1016/ j.fm.2007.09.003.

[12] Tejada-Ortigoza V, Garcia-Amezquita LE, Serna-Saldívar SO, Welti-Chanes J. Advances in the functional characterization and extraction processes of dietary fiber. Food Eng Rev. 2015; 8(3): 251-271. Available from: doi:10.1007/s12393-015-9134-y.

[13] Gibson GR, Roberfroid M. Dietary modulation of the human colonic microbiota: Introducing the concept of prebiotics. J Nutr. 1995; 125(6): 1401-1412. Available from: doi:10.1093/jn/125.6.1401.

[14] Varzakas T, Kandylis P, Dimitrellou D, Salamoura C, Zakynthinos G, Proestos C. Innovative and fortified food: Probiotics, prebiotics, GMOs, and superfood. Prep Process Relig Cult Foods. 2018; 67-129. Available from: https:// doi.org/10.1016/B978-0-08-101892-7.00006-7.

[15] Gibson GR, Scott KP, Rastall RA, et al. Dietary prebiotics: current status and new definition. Food Sci Technol Bull Funct Foods. 2010; 7(1): 1-19. Available from: doi:10.1616/1476-2137.15880.

[16] Mann J, Cummings JH, Englyst HN, et al. FAO/WHO Scientific Update on carbohydrates in human nutrition: conclusions. Eur J Clin Nutr. 2007; 61(S1): S132-S137. Available from: doi:10.1038/sj.ejcn.1602943.

[17] Rolim PM. Development of prebiotic food products and health benefits. Food Sci Technol Camp. 2015; 35(1): 3-10. Available from: doi:10.1590/1678-457X.6546.

[18] Ozcan T, Kurtuldu O. Influence of dietary fiber addition on the properties of probiotic yogurt. Int J Chem Eng Appl. 2014; 5(5): 397-401. Available from: doi:10.7763/IJCEA.2014.V5.417.

[19] Trumbo P, Schlicker S, Yates AA, Poos M. Dietary reference intakes for energy, carbohydrate, fiber, fat, fatty acids, cholesterol, protein and amino acids. J Am Diet Assoc. 2002; 102(11): 1621-1630. Available from: doi:10.1016/s00028223(02)90346-9.

[20] Velázquez M, Davies C, Marett R, Slavin JL, Feirtag JM. Effect of oligosaccharides and fibre substitutes on shortchain fatty acid production by human faecal microflora. Anaerobe. 2000; 6(2): 87-92. Available from: doi:10.1006/ anae.1999.0318.

[21] Theuwissen E, Mensink RP. Water-soluble dietary fibers and cardiovascular disease. Physiol Behav. 2008; 94(2): 285292. Available from: doi:10.1016/j.physbeh.2008.01.001.

[22] Crittenden R, Karppinen S, Ojanen S, et al. In vitrofermentation of cereal dietary fibre carbohydrates by probiotic and intestinal bacteria. $J$ Sci Food Agric. 2002; 82(8): 781-789. Available from: doi:10.1002/jsfa.1095.

[23] Tungland BC. Fructooligosaccharides and other fructans: structures and occurrence, production, regulatory aspects, food applications, and nutritional health significance. ACS Symp Ser. 2003; 135-152. Available from: doi:10.1021/bk2003-0849.ch011.

[24] Brennan CS, Tudorica CM. The role of complex carbohydrates and non-starch polysaccharides in the regulation of postprandial glucose and insulin responses in cereal foods. J Nutraceuticals Funct Med Foods. 2003; 4(2): 49-55. Available from: doi:10.1300/j133v04n02_06.

[25] Kristensen M, Jensen MG. Dietary fibres in the regulation of appetite and food intake. Importance of viscosity. Appetite. 2011; 56(1): 65-70. Available from: doi:10.1016/j.appet.2010.11.147.

[26] Tomic N, Dojnov B, Miocinovic J, et al. Enrichment of yoghurt with insoluble dietary fiber from triticale-A sensory perspective. LWT. 2017; 80: 59-66. Available from: doi:10.1016/j.1wt.2017.02.008.

[27] Dello M, E. A, Susana M, Albertengo L. Dietary fiber and availability of nutrients: A case study on Yoghurt as a food 
model. Complex World Polysacch. 2012. Available from: doi:10.5772/54031.

[28] Crispín-Isidro G, Lobato-Calleros C, Espinosa-Andrews H, Alvarez-Ramirez J, Vernon-Carter EJ. Effect of inulin and agave fructans addition on the rheological, microstructural and sensory properties of reduced-fat stirred yogurt. $L W T$ Food Sci Technol. 2015; 62(1): 438-444. Available from: doi:10.1016/j.lwt.2014.06.042.

[29] Ramaswamy HS, Basak S. Pectin and raspberry concentrate effects on the rheology of stirred commercial yogurt. $J$ Food Sci. 1992; 57(2): 357-360. Available from: doi:10.1111/j.1365-2621.1992.tb05494.x.

[30] Fiszman S, Lluch M, Salvador A. Effect of addition of gelatin on microstructure of acidic milk gels and yougurt and on their rheological properties. Int Dairy J. 1999; 9(12): 895-901. Available from: doi:10.1016/s0958-6946(00)00013-3.

[31] Thomas M, Crépeau MJ, Rumpunen K, Thibault J-F. Dietary fibre and cell-wall polysaccharides in the fruits of Japanese quince (Chaenomeles japonica). LWT-Food Sci Technol. 2000; 33(2): 124-131. Available from: doi:10.1006/ fstl.1999.0628.

[32] Chau C, Huang Y. Comparison of the chemical composition and physicochemical properties of different fibers prepared from the peel of Citrus sinensis L. Cv. Liucheng. J Agric Food Chem. 2003; 51(9): 2615-2618. Available from: doi:10.1021/jf025919b.

[33] Fügel R, Carle R, Schieber A. A novel approach to quality and authenticity control of fruit products using fractionation and characterisation of cell wall polysaccharides. Food Chem. 2004; 87(1): 141-150. Available from: doi:10.1016/ j.foodchem.2003.10.031.

[34] Praveen MA, Parvathy KRK, Balasubramanian P, Jayabalan R. An overview of extraction and purification techniques of seaweed dietary fibers for immunomodulation on gut microbiota. Trends Food Sci Technol. 2019; 92: 46-64. Available from: doi:10.1016/j.tifs.2019.08.011.

[35] Bakirci S, Dagdemir E, Boran OS, Hayaloglu AA. The effect of pumpkin fibre on quality and storage stability of reduced-fat set-type yogurt. Int J Food Sci Technol. 2016; 52(1): 180-187. Available from: doi:10.1111/ijfs.13264.

[36] Fernández-García E, McGregor JU. Fortification of sweetened plain yogurt with insoluble dietary fiber. Z Leb-Forsch A. 1997; 204(6): 433-437. Available from: doi:10.1007/s002170050108.

[37] Raju PN, Pal D. Effect of dietary fibers on physico-chemical, sensory and textural properties of Misti Dahi. J Food Sci Technol. 2014; 51(11): 3124-3133. Available from: doi:10.1007/s13197-012-0849-y.

[38] Staffolo MD, Bertola N, Martino M, Bevilacqua YA. Influence of dietary fiber addition on sensory and rheological properties of yogurt. Int Dairy J. 2004; 14(3): 263-268. Available from: doi:10.1016/j.idairyj.2003.08.004.

[39] Mohamed A, Zayan AF, Shahein M. Physiochemical and sensory evaluation of yoghurt fortified with dietary fiber and phenolic compounds. Int J Dairy Sci. 2015; 10(4): 198-205.

[40] Aziz MG, Roy J, Sarker MSH, Yusof YA. Isolation and use of bitter gourd polysaccharide in formulating dietetic soft drinks. Afr J Agric Res. 2011; 6(23): 5314-5319.

[41] Morais DR, Rotta EM, Sargi SC, et al. Proximate composition, mineral contents and fatty acid composition of the different parts and dried peels of tropical fruits cultivated in Brazil. J Braz Chem Soc. 2016. Available from: doi:10.5935/0103-5053.20160178.

[42] Chau CF, Huang YL. Characterization of passion fruit seed fibres-a potential fibre source. Food Chem. 2004; 85(2): 189-194. Available from: doi:10.1016/j.foodchem.2003.05.009.

[43] Gourgue CMP, Champ MMJ, Lozano Yves, Delort-Laval Jean. Dietary fiber from mango byproducts: Characterization and hypoglycemic effects determined by in vitro methods. J Agric Food Chem. 1992; 40(10): 1864-1868. Available from: doi:10.1021/jf00022a027.

[44] Ting SV. Alcohol-insoluble constituents of juice vesicles of citrus fruit. J Food Sci. 1970; 35(6): 757-761. Available from: doi:10.1111/j.1365-2621.1970.tb01987.x.

[45] El-Buluk R. Biochemical and physical changes in fruits of four guava cultivars during growth and development. Food Chem. 1995; 54(3): 279-282. Available from: doi:10.1016/0308-8146(95)00047-M.

[46] Femenia A, Simal S, Taberner CG, Rosselló C. Effects of heat treatment and dehydration on pineapple (Ananas comosus L. Merr) Cell Walls. Int J Food Eng. 2007; 3(2): 16. Available from: doi:10.2202/1556-3758.1097.

[47] Austin, G. Shreve’s Chemical Process Industries. Fifth Edition. McGraw-Hill; 1984.

[48] Aziz M, Andres D, Klaus D. Isolation of polysaccharides from pineapple fruit pulp and their enzymatic liquifaction. Int Food Res J. 2010; 17: 193-203.

[49] Voragen FGJ, Krist R, Heutink R, Pilnik W. Apple cell wall digestion by polysaccharide degrading enzymes. Food Process Eng. 1980; 2: 264-275. Available from: doi:10.1007/978-94-011-7795-5_29.

[50] Darvill AG, McNeil M, Albersheim P. Structure of plant cell walls: VIII. A New Pectic Polysaccharide. Plant Physiol. 1978; 62(3): 418-422. Available from: doi:10.1104/pp.62.3.418.

[51] Kip P, Meyer D, Jellema RH. Inulins improve sensoric and textural properties of low-fat yoghurts. Int Dairy J. 2006; 16(9): 1098-1103. Available from: doi:10.1016/j.idairyj.2005.10.011.

[52] Rodríguez R, Jiménez A, Fernández-Bolaños J, Guillén R, Heredia A. Dietary fibre from vegetable products as source 
of functional ingredients. Trends Food Sci Technol. 2006; 17(1): 3-15. Available from: doi:10.1016/j.tifs.2005.10.002.

[53] Chawla R, Patil GR. Soluble dietary fiber. Compr Rev Food Sci Food Saf. 2010; 9(2): 178-196. Available from: doi:10.1111/j.1541-4337.2009.00099.x.

[54] Viuda-Martos M, López-Marcos MC, Fernández-López J, Sendra E, López-Vargas JH, Pérez-Álvarez JA. Role of fiber in cardiovascular diseases: A Review. Compr Rev Food Sci Food Saf. 2010; 9(2): 240-258. Available from: doi:10.1111/j.1541-4337.2009.00102.x.

[55] Rinaldoni AN, Campderrós ME, Pérez Padilla A. Physico-chemical and sensory properties of yogurt from ultrafiltreted soy milk concentrate added with inulin. LWT-Food Sci Technol. 2012; 45(2): 142-147. Available from: doi:10.1016/j.lwt.2011.09.009. 